\title{
Símbolo e signo na estética de Hegel
}

\author{
Symbol and Sign in Hegel's Aesthetics
}

\author{
Guilherme Ferreira* \\ guilhermecicm@ufmg.br \\ (Universidade Federal de Minas Gerais, Belo Horizonte, Brasil)
}

\begin{abstract}
Resumo: Este artigo examina a concepção hegeliana de signo e a função que esse conceito cumpre no interior da estética de Hegel. Tomando por base o sentido totalizante do conceito de belo artístico como signo da ideia, o objetivo central deste artigo é mostrar que a noção hegeliana de signo cumpre um papel determinante em âmbitos específicos da estética, sobretudo, no contexto da forma de arte romântica, na qual o signo expressa a determinação sensívelespiritual mais elevada do conceito de arte. Nesse sentido, defendemos duas hipóteses. A primeira consiste em afirmar que o signo, e não o símbolo, é o elemento predominante da determinação romântica-moderna do belo artístico. A segunda sustenta que, enquanto imagem-sígnica, a bela arte romântica se define como expressão da recriação subjetiva da objetividade.
\end{abstract}

Palavras-chave: Hegel; estética; símbolo; signo; imagem-sígnica.

\begin{abstract}
This article examines the Hegelian conception of sign and the function that this concept fulfills within Hegel's aesthetic. Based on the totalizing sense of the concept of artistic beauty as a sign of the idea, the central objective of this article is to demonstrate that the Hegelian concept of sign fulfills a determining role in specific areas of aesthetics, especially in the context of the romantic art form, in which the sign expresses the highest sensitive-spiritual determination of the concept of art. In this sense, we defend two hypotheses. The first consists in affirming that the sign, and not the symbol, is the predominant element of the romantic-modern determination of the beautiful artist. The second sustains that, as a sign-image, the beautiful romantic art is defined as an expression of the subjective recreation of objectivity.
\end{abstract}

Keywords: Hegel; aesthetics; symbol; sign; sign-image.

DOI: http://dx.doi.org/10.11606/issn.2318-9800.v25i4p59-80

\section{Introdução}

Entre as inúmeras questões lançadas pela filosofia da arte de Hegel à posterioridade do debate estético vale a pena mencionar aquelas relacionadas ao caráter sígnico do belo artístico ou ideal. A definição enciclopédica e, portanto, sistemática do belo como signo da ideia [Zeichen der Idee] é apresentada pela

* O presente trabalho foi realizado com apoio da Coordenação de Aperfeiçoamento de Pessoal de Nível Superior - Brasil (Capes). Agradeço aos comentários, críticas e sugestões propostos pelos pareceristas anônimos, os quais me permitiram reparar erros, aperfeiçoar a interpretação e avançar na pesquisa. Agradeço também à Capes e à Capes-print, cujas bolsas garantem a continuidade desta pesquisa. 
primeira vez ${ }^{1}$ no $§ 556$ da Enciclopédia das ciências filosóficas de 1827, na seção “A arte", e reafirmada no mesmo tópico na Enciclopédia de $1830 .{ }^{2}$ Aqui Hegel define o belo artístico em geral como resultado do desenvolvimento da filosofia do espírito. Após se determinar de modo teórico (espírito subjetivo) e prático (espírito objetivo), o espírito agora é ressignificado e desenvolvido em um plano superior, a saber, a esfera do absoluto, a qual visa compreender e transcender às determinações teóricas e práticas do espírito humano.

A "figura da beleza" é apontada como a primeira e a mais imediata figura no curso desse saber absoluto do espírito. Essa imediatez é o "momento da finitude da arte”, é a expressividade artística que se refere não apenas ao objeto artístico, mas igualmente ao "sujeito que produz" e ao "sujeito que contempla" obras de arte. Assim, a imediatez é tanto algo externo quanto interno à subjetividade espiritual: é a imediatez finita da obra e, ao mesmo tempo, "a intuição e representação concretas do espírito em si absoluto" (Hegel, 1995, p. 341). Nesse âmbito, o "espírito em si absoluto" não se refere, pura e simplesmente, ao "espírito em si teórico", pois ele não é um "signo da ideia" que se relaciona apenas com a "imediatez natural" do si mesmo e do exterior comum. Ele é o "signo da ideia" enquanto "figura da beleza", isto é, enquanto obra de arte da transfiguração, "pelo espírito ficcional", da imediatez natural em imediatez artística.

Esta definição enciclopédica do conceito de arte como signo da ideia é integralmente compatível com a noção de belo artístico desenvolvida e apresentada por Hegel nos seus cursos de estética de Berlim. Aliás, considerando as datas de publicação das enciclopédias acima referidas, é notório que a definição do belo como signo da ideia corresponde à uma síntese geral do conceito de belo artístico ou ideal apresentado e desenvolvido nos cursos de estética de Berlim, nos anos de 1820/21, 1823, 1826, 1828/29. 3 Já considerando a própria apresentação conceitual

1 Nos Esboços de sistema de Jena de 1805/6, Hegel definiu a beleza do seguinte modo: "a beleza é antes o véu [Schleyer] que encobre a verdade do que a expressão dela mesma" (Hegel, 1976, p. 279). Embora aqui Hegel já pensasse a beleza como resultada do sistema de filosofia - embora ainda ele já tivesse uma organização clara do sistema das artes particulares, sendo, por exemplo, a "poesia natural" o início e a "poesia pura" (idem, p. 278-80) o fim do sistema particular -, Hegel ainda não dissociava o belo artístico da figura da religião, o que só ocorre a partir de 1820, nos cursos de estética e nas enciclopédias de Berlim.

2 Na Enciclopédia de Heidelberg de 1817, diferente do que ocorre nas demais enciclopédias, a arte ainda não aparece como figura autônoma, mas como "forma de contemplação" do espírito absoluto, isto é, como "religião da arte", no mesmo sentido da Fenomenologia do espírito de 1807. Sobre isso, conferir a seção "Religião da arte" da Enciclopédia de Heidelberg de 1817 (Hegel, 2001, pp. 280-82) e os §§ 556-563 da seção “A arte” da Enciclopédia de Berlim de1827 (Hegel, 1989, pp. 50012; Hegel, 1992, pp. 568-74).

3 Em relação ao primeiro curso de estética de 1818 de Heidelberg (do qual aliás restam poucos fragmentos de manuscritos), Hegel ainda trata a arte como "religião da arte", justamente como esse conceito aparece na Enciclopédia de Heidelberg de 1817. Quanto aos fragmentos de manuscritos de Hegel da época de Heidelberg restam apenas pedaços curtos de textos, incluindo uma parte que trata do conceito de objetividade da arte e uma segunda parte que trata do conceito de fantasia simbólica. Esses poucos fragmentos foram editados e já se encontram publicados no volume 18 
do belo artístico na primeira parte da estética é interessante observar ainda - e nesse sentido concordamos com a interpretação de Jaeschke (2020, p. 320) - que "Hegel não desenvolve o conceito de arte a partir do conceito de beleza", mas antes "a partir do conceito de autoconhecimento do espírito". Nas palavras do próprio Hegel, "para nós o conceito do belo e da arte são um pressuposto dado pelo sistema de filosofia” (Hegel, 1999, p. 47).

A definição do belo apresentada de modo sintético pela enciclopédia é exposta de forma ampliada na primeira parte da estética, no tópico "A ideia do belo artístico ou ideal”. Aqui Hegel afirma o seguinte: "a Ideia não é apenas verdadeira, mas também bela. 0 belo se determina, desse modo, como aparência [Scheinen] sensível da ideia" (idem, p. 126). Embora o termo Zeichen der Idee seja aqui substituído por Scheinen der Idee, a significação de ambos é a mesma. Assim como ocorre na Enciclopédia, o conceito de belo artístico é aqui apresentado como contendo os mesmos dois lados espiritualmente interpenetrados (o lado da imediatez da figura e o lado da imediatez do espírito). Esse “duplo aspecto” é aqui descrito do seguinte modo: "em primeiro lugar, um conteúdo, uma finalidade, um significado; a seguir, a expressão, o fenômeno e a realidade deste conteúdo, em terceiro lugar, os dois aspectos de tal modo interpenetrados que o exterior e particular aparecem exclusivamente como exposição do interior" (idem, p. 110). Em geral, é esse duplo aspecto que define o belo artístico em Hegel. Como nos lembra Jaeschke (2020, p. 326), "isso determina se uma obra deve ser entendida como uma obra de arte, como um 'signo da ideia'”.

Considerando este sentido totalizante (o duplo aspecto) do conceito de belo artístico como signo da ideia, o presente trabalho propõe analisar a noção de signo precisamente em relação à função que o signo cumpre em âmbitos mais específicos da estética de Hegel, a saber, no domínio da particularização histórica da arte e na esfera particular da obra de arte. O objetivo central dessa análise é mostrar que a noção hegeliana de signo cumpre um papel determinante em âmbitos específicos da estética, sobretudo, no contexto da forma de arte romântica, na qual o signo figura a determinação sensível-espiritual mais elevada do conceito de arte. Nesse sentido, defendemos duas hipóteses. A primeira consiste em afirmar que o signo, e não o símbolo, é o elemento predominante da determinação romântica-moderna do belo artístico. A segunda sustenta que, enquanto imagem-sígnica, a beleza romântica se define como expressão da recriação subjetiva da objetividade.

O nosso trabalho está dividido do seguinte modo. Em primeiro lugar, analisamos a relação forma/conteúdo apresentada por Hegel no domínio da forma de arte simbólica. Na arte simbólica, os conceitos de símbolo e signo são apresentados por Hegel sob dois pontos de vista distintos: um estritamente formal, no sentido

(que reúne diversos manuscritos de cursos ofertados por Hegel entre 1816 e 1831) da coleção Gesammelte Werke-Hegel (cf. Hegel, 1995, pp. 115-117). 
do Formalismus hiperconcentrado na forma [Gestalt] em detrimento do conteúdo [Inhalt]; e outro que considera o "duplo aspecto" (conteúdo, significado, finalidade/ expressão, fenômeno e realidade) como unidade conceitual da arte simbólica. O objetivo aqui é mostrar que o conceito de símbolo não extrapola o âmbito da forma de arte simbólica. Em segundo lugar, avaliamos a relação forma/conteúdo apresentada por Hegel no âmbito da forma de arte romântica-moderna, na qual os conceitos de símbolo e signo são ressignificados segundo as exigências postas pelo contexto artístico romântico-moderno. 0 objetivo aqui é mostrar que a arte romântica-moderna é predominantemente sígnica e não simbólica. Nesse registro, veremos, o conceito de signo é inscrito como marca sensível da emancipação da subjetividade de sua relação de dependência para com a exterioridade.

Em terceiro lugar, visando esmiuçar sobretudo os conceitos de símbolo e signo, recorreremos à Enciclopédia das ciências filosóficas. Esse procedimento se justifica por dois motivos. Por um lado, é no âmbito da Enciclopédia que as principais categorias da estética de Hegel são formuladas e estruturadas. Por outro lado, nesse registro, encontramos uma articulação minuciosa de categorias que reaparecem em âmbitos mais específicos (da história da arte e da obra de arte) da estética de Hegel. Esse é o caso, por exemplo, do movimento de passagem da intuição sensível à representação sensível e a relação desse movimento com os conceitos de fantasia simbolizante, fantasia significante, símbolo e signo, conceitos os quais interessam particularmente à nossa proposta. Ao final dessa última parte concluímos que o signo (o qual nomeamos de imagem-sígnica) está para a definição da arte romântica na mesma proporção em que o símbolo está para a forma de arte simbólica. Enquanto elemento sensível predominante da beleza romântica-moderna, a noção de signo funciona como uma espécie de termômetro, que mede o grau de espiritualização da arte e a capacidade do artista em trazer à exterioridade um conteúdo artístico substancial, que apareça tanto como expressão quanto como recriação do espírito.

As noções de símbolo e signo já foram, sob outros pontos de vistas, analisadas e discutidas por intérpretes hegelianos. Embora neste texto não tenhamos espaço para debater as teses já defendidas sobre o assunto, é preciso lembrar rapidamente aquelas entre as quais a nossa proposta mais se aproxima. Paul De Man (1982, p. 764), por exemplo, sustenta que a definição do belo "poderia ser mais bem traduzida pela afirmação: o belo é simbólico". ${ }^{4}$ Mário Farina (2015, p. 17-18) se concentra nos aspectos particular e singular do sistema das artes para mostrar que o simbólico é o

\footnotetext{
4 Nesse sentido, De Man mobiliza concepções semióticas de símbolo e signo para propor, grosso modo, duas conclusões: a) que "a teoria estética, tanto como noção histórica quanto como noção filosófica, é predicada, em Hegel, em uma teoria da arte simbólica" e 2) que "teoria estética e história da arte são as duas partes complementares de um único symbolon" (1982, p. 764) e que "o que a estética chama de belo é algo muito distante do que associamos à sugestividade da forma simbólica" (idem, p. 763).
} 
conceito central da estética de Hegel. ${ }^{5}$ Já Peter Szondi (1974, p. 395 apud De Man, 1986, p. 765) propõe algo mais polêmico, ao defender que Hegel não compreendeu de modo adequado os conceitos de símbolo e signo e que, nesse aspecto, a sua estética figura um discurso ultrapassado. ${ }^{6}$

No que se refere ao conceito de representação sensível, que será essencial à nossa abordagem, lembramos as teses de Marco Aurélio Werle e Henri Lauener. De modo geral, Werle (2005, p. 17) defende que "somente o conceito de representação permite compreender as diferentes implicações que a arte da poesia assume no contexto da estética de Hegel, enfim, permite definir a poesia como tal”. Henri Lauener (2004, p. 105), sob o ponto de vista da linguagem, defende que o aspecto linguístico da "expressão poética" é apenas um sinal para a "representação poética". ${ }^{7}$

\section{A forma e o conteúdo da beleza simbólica}

Ao analisar o conceito de símbolo em geral, Hegel deixa clara a delimitação de sua análise ao afirmar que seu esforço "não consiste em verificar em que medida formas artísticas poderiam ser interpretadas simbólica e alegoricamente, mas de perguntar, inversamente, em que medida o simbólico há de ser creditado à forma da arte" (Hegel, 2000, p. 35). Para Hegel, o símbolo "ao invés de constituir representações indeterminadamente universais e abstratas, termina imediatamente onde a individualidade livre constitui o conteúdo e a forma da exposição" (idem, ibidem).

Nesse sentido, Hegel recusa a interpretação romântica do símbolo na arte. Ao contrário do romantismo de Friedrich von Schlegel - o qual defende que "toda beleza é alegórica” (Schlegel, 1994, p. 58) e que "em cada exposição artística há de se procurar uma alegoria" (Hegel, 2000, p. 34) -, Hegel acredita que o alegórico e o simbólico são representações do entendimento e que, por isso mesmo, destroem a forma artística na medida em que neles está contida a cisão abstrata e irreconciliável entre imagem e significado. Tomado como mero pressuposto formal e abstrato da arte, o símbolo se determina como um dispositivo do entendimento separador, que

5 Nesse sentido, Farina defende duas teses: a) que "a concepção hegeliana do símbolo sofre necessariamente uma transfiguração completa” (2015, p. 18), à medida que o símbolo se transforma em expressão do caráter crítico-reflexivo da arte em geral; e b) com base nessa transfiguração do conceito de símbolo, a estética de Hegel se caracteriza como "a teoria da arte capaz de lidar com a tensão entre o elemento formal, ideal, da obra e sua natureza histórica e de conteúdo (idem, p. $17)$.

6 Por um lado, diz Szondi, porque a arte "certamente tende a cada vez mais produzir imagens e metáforas como sua característica essencial" e, por outro lado, porque "Hegel não consegue atingir uma compreensão adequada da metáfora e do símile" (1974, p. 395 apud De Man, 1986, p. 765).

7 Assim, diz Lauener, "não é a escolha das palavras singulares e sua hábil composição que estipulam uma verdadeira origem da linguagem artística, mas muito mais a forma da representação", razão pela qual, então, Hegel dá a representação culta como ponto de partida da expressão culta" (2004, pp. 105-106). 
permite apenas extrair da singularidade artística "o universal enquanto tal” (idem, ibidem) por meio da comparação entre expressão e significado. Todavia, essa é uma compreensão inadequada à arte, uma vez que ela (a arte) se refere ao que há de mais concreto no espírito: a "individualidade livre”. Para Hegel, na arte, o que deve ser ressaltado enquanto expressão e conteúdo autêntico é a subjetividade livre, "pois o sujeito é o significativo por si mesmo e o que se explica a si mesmo" (idem, p. 35). Nesse sentido, o simbólico deve permanecer restrito apenas ao âmbito da "pré-arte", pois é apenas nesse registro que os dois lados do símbolo, a forma e o conteúdo, se articulam em termos de separação formal.

No âmbito da pré-arte, a separação formal entre a imagem artística e o significado espiritual, que nela está contido de modo abstrato, corresponde imediatamente a condição rudimentar da liberdade individual a qual, por sua vez, ainda é marcada pela cisão entre o universal e o particular. Em outras palavras, o simbólico só pode ser compreendido em sua particularidade formal e efetividade a partir do contexto cujo caráter de cisão concreta entre subjetividade e objetividade está inscrito como conteúdo espiritual. Esse contexto é classificado por Hegel como sendo o "ideal simbólico", o qual se distingue fundamentalmente dos ideais "clássico" e "romântico".

A asserção de Hegel de que o símbolo constitui o início e o momento mais rudimentar da arte, tanto do ponto de vista de seu conceito quanto de sua expressão histórica, ocorre na introdução da segunda parte dos Cursos de estética, na seção que trata do primeiro desenvolvimento particular do belo artístico, a forma de arte simbólica. Neste horizonte de compreensão, Hegel estabelece uma distinção precisa entre o símbolo compreendido em "sua peculiaridade autônoma, na qual ele fornece o tipo preponderante para a intuição artística e a exposição, e o símbolo "reduzido à mera forma externa, não autônoma para si mesma” (Hegel, 2000, p. 25). Essa caracterização dupla do conceito de símbolo é de crucial importância para Hegel, pois é a partir dela que o nosso autor se recusa a pensar o símbolo como uma função determinante da arte em geral, ao contrário da tendência de sua época, que se inclinou ao uso cada vez mais comum dos conceitos de símbolo, alegoria e metáfora para pensar os clássicos da produção artística, desde as mitologias antigas até Dante. ${ }^{8}$

Compreendido em termos formais e abstrato, o símbolo é uma imagem exterior "imediatamente presente ou dada para a intuição" (idem, p. 26), a qual possui um significado que não deve ser entendido por meio da simples imediatez sensível, mas que sempre aponta para algo outro, um universal abstrato. Isso quer

8 Sobre essa tendência, Hegel faz a seguinte crítica: "Recentemente, este modo de tratamento tornou-se igualmente muito comum. Assim, por exemplo, procurou-se explicar nas recentes edições de Dante, onde sem dúvida aparecem múltiplas alegorias, cada canto completamente de modo alegórico, e também as edições de Heyne de poetas antigos procuraram esclarecer nas notas o sentido universal de cada metáfora por meio de determinações abstratas do entendimento" (Hegel, 2000, p. 37). 
dizer que a imagem simbólica contém em si dois lados: a expressão imediata e o significado mediado da expressão. O significado mediado é uma representação, independentemente de qual conteúdo esteja contido nela. Por outro lado, a imagem imediata é uma existência sensível que não possui nenhuma outra determinação senão a sua própria determinidade imediata. Isso demonstra que o símbolo contém em si uma cisão, que reduz a sua função à "elevação diante da representação de um conteúdo estranho a ela" (idem, ibidem). Determinado desse modo, o símbolo é também um signo. Hegel fornece dois exemplos a respeito do signo, os quais indicam o caráter sígnico do símbolo. Ele exemplifica que "os sons nas línguas são signos de alguma representação, sensação [Empfindung]" (idem, ibidem.), e nisso reside a arbitrariedade de que uma única representação pode ser expressa de diversos modos, assim como no caso das cores nos emblemas e nas flâmulas reside uma necessária arbitrariedade, já que a "cor não contém igualmente nenhuma qualidade que fosse comum ao seu significado" (idem, ibidem).

Todavia, por outro lado, é por meio do signo que se alcança a determinação do símbolo. Por exemplo, o leão "é tomado como o símbolo da força e a raposa como símbolo da coragem” (Hegel, 2000, p. 26). Nesse caso, a imagem simbólica não é marcada por um vazio em termos de significação, mas contém em si a indicação de algo, de um universal abstrato; o que importa nesse caso é muito mais o significado inscrito na imagem do que a imagem em si mesma.

Segundo Hegel, é por meio desta inadequação entre a imagem e o significado que o símbolo se define. A forma simbólica contém em si diversas determinações, "completamente independentes daquela qualidade comum que ela uma vez significou" (idem, p. 27), assim como o conteúdo pode não ser apenas uma representação abstrata, mas sim um elemento efetivo que possui qualidades diferentes daquilo para o qual ele inicialmente se constitui. Portanto, em se tratando do símbolo formalmente determinado, a ambiguidade prevalece como essencialidade, pois "o conteúdo permanece indiferente frente à forma que o representa; e a determinidade que ele constitui pode estar presente de igual modo em outras infinitas existências e configurações" (idem, ibidem).

Embora esta ambiguidade entre expressão e conteúdo seja algo irreconciliável na forma do símbolo, Hegel indica uma solução para este caráter de dubiedade que, ao mesmo tempo, desvela outros aspectos relacionados ao símbolo, a saber, a metáfora e a similitude. A qualidade metafórica implicada no símbolo é determinada pela suspensão da cisão entre os lados do significado e da forma, de modo que ambos são destacados ao mesmo tempo e explicitamente no ato expressivo. Hegel também nomeia o símile de a "forma da comparação", pois, apesar da imagem ser acrescida de significado, ainda assim o significado permanece cindido pela expressão. Hegel cita como exemplo uma das falas da personagem Karl Moor, do drama os bandoleiros de Schiller, na cena em quem ele discursa sobre o pôr-do-sol: "Assim morre um 
herói!" (idem, p. 29). Outro exemplo é a passagem do Antigo Testamento que diz: "Deus, quebre os seus dentes na sua boca; senhor, esmague as presas dos jovens leões!” (idem, p. 30). Hegel explica que, em ambos os casos, o objeto é tomado como imagem, a boca, os dentes, as presas, devem ser entendidas como coisas inautênticas em si mesmas, as quais se referem apenas ao sensível que elas projetam para um dado significado. 0 símbolo, a exemplo desse caso, é um símile elevado ao hábito na relação de comparação. Isto é, ao contrário do símile, o símbolo ocorre quando o significado é expresso por si mesmo de modo claro, quando o significado se torna uma convenção que remove da imagem toda a sua ambiguidade. Em outras palavras, o símbolo autêntico ocorre quando a ambiguidade envolvida na relação entre imagem e significado "se torna algo em maior ou menor grau convencional" (idem, p. 30). Por exemplo, a imagem do triângulo no mundo cristão é produto de uma construção simbólica da trindade, algo que, uma vez representado fora deste contexto, implica a suspensão de toda convenção.

Esta determinação do simbólico como imagem convencional configura-se como o ponto nuclear da discussão hegeliana sobre o conceito de símbolo, uma vez que é por meio dessa determinação que o simbólico deixa de ser pensado a partir de casos isolados, ou mesmo a partir da relação meramente formal entre imagem e significado, e passa a ser compreendido como um âmbito ideal que, a exemplo da arte simbólica, envolve "o conteúdo de quase a totalidade da arte oriental" (Hegel, 2000, p. 30). Nesse sentido, o simbólico é tomado como conteúdo da "pré-arte". Mais do que se referir à forma ou às condições materiais da exposição artística, o belo simbólico se orienta por uma dada condição de mundo, a qual implica uma colocação particularizada da subjetividade em termos de sua relação com a objetividade. Dito de outro modo, sendo a arte uma atividade referida ao que há de mais concreto e imediato no espírito (a subjetividade livre), o que a determina em sua autêntica verdade deve igualmente ser da ordem do concreto, isto é, da ordem do conteúdo [Gehalt] espiritual.

É exatamente por causa da sua deficiência em termos de conteúdo [Gehalt] de verdade espiritual que a forma simbólica se apresenta como uma exposição ainda rudimentar da arte. Tanto a expressão da arte quanto as condições de subjetividade nela implicada como seu conteúdo autêntico ainda são dimensões pouco desenvolvidas em termos daquilo que faz da arte uma expressão elevada do espírito, isto é, a liberdade e posicionamento concretos acima das limitações e determinações teóricas e práticas da vida. 0 estado simbólico revela, em um primeiro momento, que a subjetividade espiritual ainda se encontra numa relação de "unidade imediata com o absoluto", sem nenhuma separação que diferencie a interioridade subjetiva da exterioridade objetiva. Nem a natureza é determinada enquanto tal, nem o espírito se encontra emancipado por si dela. Ainda não existe diferença substantiva entre alma e corpo, conceito e realidade, natureza e espírito, toda aparência imediata 
se reduz a uma única determinação: o divino. Hegel cita por exemplo a religião de Zoroastro, ${ }^{9}$ que "considera como o absoluto a luz em sua existência natural, o sol, os corpos celestes e o fogo em seu brilhar e flamejar, sem separar este divino para si da luz, enquanto uma mera expressão e retrato ou imagem sensível" (idem, p. 49). Trata-se ainda de um estado religioso e não propriamente artístico na medida em que tal unidade imediata com o absoluto se mantém condicionada à objetos da natureza e atividades humanas.

Em outra versão mais elevada do estado de mundo simbólico, "o simbolismo do sublime", a clareza do significado da imagem, separado do mundo da totalidade fenomênica, impõe uma primeira separação entre o humano e o divino, o finito e o infinito, a natureza e o espírito, algo que rompe a unidade imediata com o absoluto, imposta ao estágio anterior. Em se tratando de significado espiritual, a arte sublime é determinada como a atividade que demarca a finitude humana frente à grandeza de Deus. Nela o significado espiritual ainda não é apreendido de modo concreto, “mas ele é, porém, considerado como o interior que existe em si e repousa em si mesmo, o qual é incapaz segundo a sua natureza de encontrar a sua verdadeira expressão em fenômenos finitos” (Hegel, 2000, p. 49). Não é por acaso que, em se tratando do aspecto formal da expressão, a arte sublime quando muito consegue comunicar o excesso destituído de significado imediato; esse significado é apenas simbolizado pela imagem. Se no simbolismo inconsciente a deficiência é marcada pela indistinção entre significado e forma, na arte sublime, ao contrário, tal deficiência se encontra na própria cisão abstrata entre os dois lados, cujo resultado mantém o significado espiritual como uma qualidade meramente abstrata e intelectual. 0 poeta maometano, por exemplo, "anseia por ver e efetivamente vê o divino em tudo", mas, em contrapartida, ele também "renuncia ao seu próprio si-mesmo [Selbst] e apreende igualmente a imanência do divino em seu interior" (idem, p. 93). Nesse sentido, o conteúdo espiritual e o modo de expressão da imagem se mantém presos a uma relação simbólica. Do lado do significado espiritual, o indivíduo é determinado a representar apenas um ente abstrato no interior de si mesmo (Deus), diferente de si mesmo. Do lado da imagem, igualmente, o que se manifesta imediatamente como forma é sempre esvaziado de sentido próprio, remetendo à um significado outro, um universal abstrato.

Percebe-se, portanto, que o belo simbólico “constitui representações indeterminadamente universais e abstratas" (idem, p. 35), o que sugere igualmente um traço residual e enigmático no desenvolvimento da subjetividade espiritual. Ao considerarmos o "duplo aspecto" do belo artístico (conteúdo, significado, finalidade/ expressão, fenômeno e realidade) no âmbito do desenvolvimento conceitual da arte

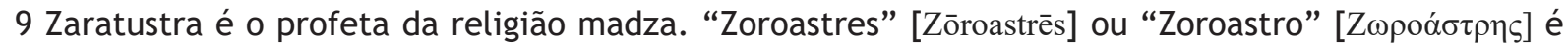
uma nomeação helênica do profeta e poeta Persa Zaratustra (VII a.C.). O Masdeísmo ou Zoroastrismo, é considerada a primeira religião monoteísta da história. Sobre isso conferir: Hegel, 2000, p. 49-53. 
simbólica, percebemos que o conceito de símbolo, enquanto elemento expressivo da arte, não extrapola o âmbito da forma de arte simbólica. Todavia, por outro lado, na arte romântica-moderna - o extremo oposto da forma de arte simbólica e o âmbito mais elevado da formação sensível-espiritual - a noção de símbolo é retomada e ressignificada. Hegel afirma que a arte romântica, em certo grau, "é um retorno ao simbólico, na medida em que o que ele fornece não é uma exposição [Darstellung] clara, aberta, do interior inteiro, mas apenas um signo, uma alusão" (idem, p.318). Ora, como podemos interpretar esta afirmação da arte romântica como arte sígnica, alusiva? Qual a diferença essencial entre símbolo e signo no contexto da bela arte romântica? Em que sentido o signo, e não o símbolo, é o elemento predominante da determinação romântica-moderna do belo artístico? Passemos a análise da forma de arte romântica, na qual encontraremos respostas à essas questões.

\section{A forma e o conteúdo da beleza romântica}

O princípio da arte romântica, também nomeada de "beleza espiritual do interior" (Hegel, 2000, p. 253), é a subjetividade livre, ou, se preferirmos, a subjetividade sensivelmente emancipada de sua relação de dependência da exterioridade. A liberdade, nesse sentido, está relacionada ao desprendimento da subjetividade de sua relação sensivelmente estabelecida com a exterioridade objetiva. Aquilo que outrora estava condicionado à intuição sensível, isto é, a apreensão do absoluto por meio da própria exterioridade, agora se estrutura como propriedade interior, como conteúdo que habita o sujeito. Subjetividade, porém, não deve ser entendida como mera relação teórica entre o entendimento ${ }^{10}$ e a coisa interiormente representada como fenômeno, mas sim como subjetividade espiritual. Nas palavras de Hegel, o momento da beleza espiritual interior é o estágio de formação pela arte no qual o espírito "apenas pode encontrar sua existência correspondente em seu mundo espiritual familiar próprio do sentimento, do ânimo, em geral, da interioridade" (idem, p. 252). Nesse caso, a realidade exterior é retratada pelo sujeito como "uma existência que não lhe é adequada" (idem, p. 253), uma existência que não corresponde de modo satisfatório às vicissitudes e aspirações mais elevadas. A realidade exterior no registro romântico da arte pode

10 Hegel contrapõe o "entendimento separador" ao "entendimento intuitivo". Aqui nos referimos especificamente ao entendimento intuitivo. Sobre esta distinção, o $\S 55$ da Enciclopédia é bastante esclarecedor. Diz Hegel: “A Crítica da faculdade de julgar tem de notável que Kant exprimiu nela a representação, e mesmo o pensamento, da ideia. A representação de um entendimento intuitivo, de uma finalidade interna etc. e o universal pensado ao mesmo tempo como concreto em si mesmo. Por isso, a filosofia kantiana só se mostra especulativa nessas representações. Muitos - nomeadamente Schiller - descobriram na ideia do belo artístico, da unidade concreta do pensamento e da representação sensível, a saída [para escapar] das abstrações do entendimento separador. Outros a descobriram na intuição e na consciência da vida [lebendigkeit, vitalidade] geralmente falando, quer natural quer intelectual” (1995b, § 55, p. 131). 
assim ser considerada uma dimensão periférica da vida do espírito. Ao contrário do que ela significou para o indivíduo no contexto simbólico, a saber, uma propriedade natural cuja essencialidade se servia como totalidade abstrata da alma, no contexto romântico esta mesma exterioridade é vislumbrada como opacidade, cuja essência e luminosidade reside na interioridade subjetiva. Trata-se da "desdivinização [Entgötterung] da natureza" (idem, p. 259) e, ao mesmo tempo, da "divinização do humano", isto é, a elevação da subjetividade espiritual à dignidade absoluta por meio dela própria.

Hegel considera três determinações distintas no âmbito da beleza romântica, as quais são respectivamente denominadas de círculo religioso-cristão, círculo da mundanidade e círculo da autonomia formal do caráter. Quanto ao primeiro círculo, que está ligado diretamente à formação [Bildung] religiosa da subjetividade, Hegel diz que se trata de um momento de extrema modificação no conceito de subjetividade, uma vez que a história da "redenção, a vida, a morte e a ressureição de Cristo" (Hegel, 2000, p. 252) fornece o conteúdo [Gehalt] central a ser perscrutado pela subjetividade artística, de modo completamente diferente daquele presente no contexto das artes simbólica e clássica. Pois Cristo é quem apresenta pela primeira vez um modelo concreto de subjetividade, pautada na "negatividade absoluta" e a sua posição de colisão direta com a existência objetiva. Negatividade absoluta deve aqui ser compreendida como a determinação segundo a qual "o espírito se volta negativamente contra a sua imediatez e finitude, a supera e, por meio desta libertação, conquista para si sua infinitude e autonomia absoluta em seu próprio âmbito" (idem, p. 262). Nesse sentido, Cristo é a figura que, pela primeira vez na história, nega a sua própria corporeidade, assim como, a partir de uma atitude inteiramente hostil e adversa frente à natureza finita do humano, nega o lado negativo da subjetividade. "A negação do que é negativo" (idem, p. 258) no contexto romântico não é outra coisa senão a negação daquilo que faz com que a dimensão afirmativa da vida a torne negativa, isto é, a morte. A mera finitude corporal e vivencial, assim como a mera naturalidade enquanto um dos lados da vida, são tratadas como inadequação entre o subjetivo e o objetivo, o natural e o espiritual, ao passo que a interioridade subjetiva, por meio de sua negatividade e liberdade absoluta, se assegura como infinitude concreta em si e a partir de si mesma.

Mas a subjetividade livre vai além dessa condição de formação religiosa, na medida em que avança em direção à superação [Aufheben] do próprio Cristo. Uma vez que a figura do Cristo se estabeleceu como conteúdo absoluto para a subjetividade, de modo que a negatividade absoluta se configurou como propriedade estruturante da relação entre interioridade e exterioridade, é a partir desse exemplo igualmente que o sujeito passa a negar a própria "divindade do espírito". Assim, "a honra, o amor, a fidelidade e a coragem" (idem, p. 263), enquanto dimensões finitas do humano, se tornam os conteúdos afirmativos do espírito. É interessante notar, neste 
segundo círculo da arte romântica, que a subjetividade espiritual é determinada não apenas pelo processo da "desdivinização da natureza", mas, igualmente, pela "desdivinização de Deus". Isto é, assim como a natureza e a exterioridade que dela resulta passaram a ser negadas pelo sujeito, assim também Deus passa a ser refutado como conteúdo absoluto. Isso porque, na medida em que o Deus se fez homem, e, por outro lado, se posicionou como superior ao caráter finito da condição humana, ao mesmo tempo, ele indicou o caminho da "divinização do humano". Nesta direção, a honra, o amor, a fidelidade e a coragem são determinadas como conteúdos particulares e formais, cujo fundamento concreto se encontra instituído na própria deificação da subjetividade.

O lado extremo deste processo de deificação da subjetividade pode ser notado a partir do "círculo da autonomia formal do caráter", o último âmbito da arte romântica. Aqui é a autonomia espiritual do caráter que constitui o conteúdo [Gehalt] a ser apresentado pela arte. Nesse registro, os conteúdos particulares de cada indivíduo singular se impõem como conteúdos válidos universalmente, isto é, a particularidade do conteúdo é o que constitui essencialmente o mundo do sujeito. Nesse sentido, a "firmeza do caráter" se mostra como uma totalidade circunscrita ao em-si-para-si-mesmo de cada indivíduo singular, algo que pressupõe um formalismo atravessado pela contingência. Entretanto, formalismo aqui não deve ser entendido de modo idêntico ao que foi considerado anteriormente a respeito do formalismo simbólico, o qual pressupunha uma relação abstrata entre a interioridade subjetiva e exterioridade objetiva. Ao contrário disso, o formalismo do estágio atual diz respeito ao fato de que a determinação subjetiva, aquilo que o sujeito é, não é sustentado nem por uma certa substancialidade objetivamente determinada nem pelo que está interiormente determinado como conteúdo principal; a particularização nesse caso pressupõe uma certa cisão do indivíduo consigo mesmo, entre o que the é próprio enquanto conteúdo substancial e o que the é contingente ou meramente psicológico. Nas palavras de Hegel, o sujeito nesse estágio "em vez de repousar sobre o conteúdo e sobre seu pathos para si mesmo firme, apenas repousa formalmente sobre sua própria autonomia individual” (Hegel, 2000, p. 312).

Nesse sentido, o formalismo do caráter é marcado por um jogo que possui dois lados principais: por um lado, a "firmeza do caráter" que é por si mesma uma espécie de cegueira em relação aos conteúdos substancialmente determinados no interior do ânimo e, por outro lado, o caráter determinado como "totalidade subjetiva" (idem, ibidem), o pathos legitimado interiormente como algo firme, substancial. Essa totalidade subjetiva, a qual possui em si mesma uma base forte de sustentação espiritual, não deve, todavia, ser confundida com a substancialidade ética, a qual está pautada numa espécie de paixão e fidelidade plena do indivíduo para com a eticidade. Aqui o movimento é inverso: o conteúdo espiritual já é uma propriedade exclusiva do ânimo, o qual ainda precisa eclodir [austreten] e se efetivar objetivamente. Esse 
processo de externalização do conteúdo espiritual não é uma tarefa fácil para a arte, embora seja exatamente essa a tarefa central da arte romântica. Fazer eclodir um conteúdo substancial desde o ânimo humano pode ser comparado, segundo Hegel, a "uma pedra rara, que apenas cintila [scheinen] em pontos singulares, um cintilar que é como um relâmpago" (Hegel, 2000, p. 316).

Os principais exemplos citados por Hegel quanto a esses dois lados do caráter (a firmeza de natureza psicológica e a firmeza determinada como totalidade subjetiva) são extraídos de Shakespeare: Macbeth e Julieta de Romeu e Julieta. Por um lado, diz Hegel, temos a "firmeza sem escrúpulos" de Macbeth, que "é determinado por seu caráter para a paixão da ambição. No início ele hesita, mas então estende a mão à coroa, comete o assassinato para alcançá-la, e para afirmá-la comete todas as atrocidades" (idem, p.313). Aqui vemos a natureza psicológica e puramente formal da subjetividade em sua relação consigo mesma. Nesse estado de coisas, o impulso [Trieb] de Macbeth não indica de nenhum modo um conteúdo espiritual cuja firmeza do caráter se mantém ancorada. Por outro lado, temos o contraexemplo de Julieta, a qual inicialmente aparenta ser uma figura ingênua, uma moça com pouca experiência, sem "nenhuma consciência de si e do mundo" (idem, p.317), mas que, "de repente, vemos o desenvolvimento da energia inteira desse ânimo, da astúcia, da circunspecção, da força para sacrificar tudo, para submeter-se ao que é mais duro, de modo que o todo nos aparece" (idem, ibidem). A totalidade como conteúdo [Gehalt] nada mais é senão o amor levado, em um piscar de olhos, às suas consequências mais radicais. Nas palavras de Hegel, trata-se de um conteúdo profundo da alma, que em seu progredir e externar-se se compara a um "incêndio que uma única faísca provocou, um botão que, mal tocado pelo amor, inesperadamente se apresenta em plena florescência; mas quanto mais rapidamente se desenvolve, tanto mais rapidamente perde suas pétalas e morre" (idem, ibidem).

Considerando esse "duplo aspecto" da autonomia do caráter, percebe-se que a arte romântica-moderna se define como "signo da ideia", cuja progressão e desenvolvimento do conteúdo possui como ponto de partida a própria interioridade subjetiva. Nesse sentido, temos uma primeira compreensão importante a respeito da predominância sígnica da beleza romântica frente à beleza simbólica. Pois, se no estágio simbólico da arte o conteúdo de verdade do espírito é determinado como propriedade exterior, seja ela religiosa seja ela a própria natureza e, se o domínio da relação entre o subjetivo e o objetivo é estabelecido pela intuição formal e abstrata da exterioridade (o símbolo), no estágio romântico, ao contrário, a progressão e o desenvolvimento do conteúdo de verdade do espírito tem seu começo no próprio sujeito, o qual se torna para si mesmo o seu próprio juiz. Contudo, é importante notar que este conteúdo de verdade permanece na forma da interioridade subjetiva como uma representação que ainda precisa encontrar sua colocação e expressão em uma forma determinadamente objetiva (o signo). 
Neste ponto surge um aparente obstáculo imposto à arte, qual seja, o do seu potencial de trazer à expressão o conteúdo inteiro do espírito, que agora se mantém circunscrito à interioridade subjetiva. Sobre isso, podemos perguntar: como pode a arte tornar manifestos os conteúdos que agora se mantém particularizados, dispersos e fragmentados no interior do peito humano, de modo a se manter como autêntica expressão do absoluto? Segundo Hegel, isso que a princípio parece se tratar de um empecilho à expressividade artística deve na verdade ser compreendido como a sua mais elevada determinação. Ou seja, se o conteúdo de verdade da arte não pode mais ser expresso como conteúdo unificado por meio de um único princípio universalmente e objetivamente válido - exatamente porque aquilo que era substancial agora está determinado como particularidade e multiplicidade da alma - então, para a arte, só resta a tarefa de tornar manifesto o absoluto em sua particularidade e dissolução. Hegel nos fornece um exemplo deste processo. Ao citar os cantos populares principalmente os cantos germânicos Hegel afirma, por um lado, que eles quando muito "apenas são capazes de levar a exteriorizações esfarrapadas" dos conteúdos substanciais, mas, por outro lado, é exatamente por meio disso que eles "revelam a profundidade da alma" (Hegel, 2000, p. 317).

Mas não seria esta condição esfacelada, esfarrapada, fragmentada da expressividade artística uma remissão patente ao seu estágio simbólico, uma vez que o símbolo é exatamente uma representação que não encontra outra correspondência objetiva senão aquela ligada à analogia, à metáfora como produto da relação entre interioridade e exterioridade? Para Hegel, se trata exatamente disso, pois "este é um modo de representação [Darstellung], que em sua mudez, por assim dizer, retorna ao simbólico, na medida em que o que ele fornece não é uma exposição [Darstellung] clara, aberta, do interior inteiro, mas apenas um signo, uma alusão" (idem, p. 318). Vale lembrar, todavia, que não se trata de "um símbolo cujo significado, como anteriormente, permanece uma universalidade abstrata, mas uma exteriorização cujo interior é justamente este ânimo subjetivo, vivo, efetivo mesmo" (idem, ibidem). Esse "novo símbolo" é o signo ou a imagem-sígnica da bela arte romântica, o qual justamente se caracteriza como exteriorização do ânimo subjetivo-espiritual.

Como pudemos notar até aqui, o ponto central da determinação simbólica ou romântica do belo artístico está diretamente ligado ao modo como a subjetividade se relaciona com os seus conteúdos de verdade, assim como está ligado ao modo da expressão objetiva desses conteúdos espirituais. Na forma da intuição sensível a subjetividade é menos livre e mais dependente da exterioridade, pois neste grau de desenvolvimento os conteúdos espirituais ainda são propriedades do objeto sensível. Na forma da representação sensível, ao contrário, a subjetividade é mais livre porque independe do objeto sensível para representar interiormente os seus conteúdos.

Nessa direção, precisamos responder a três questões que ainda permanecem latentes: a) como Hegel define os conceitos de intuição sensível e representação 
sensível? b) nesse caso, o que significa dizer que o belo artístico romântico é predominantemente sígnico e não simbólico? c) em que sentido a imagem-sígnica se define como expressão da recriação subjetiva da objetividade no contexto da beleza romântica? Passemos à análise dessas questões tomando por base a Enciclopédia das ciências filosóficas, especialmente nos parágrafos em que as categorias da intuição [Anschauung] e da representação [Vorstellung] são formuladas e estruturadas por Hegel. A propósito, é exatamente nesse âmbito que podemos identificar um desdobramento minucioso a respeito da distinção entre símbolo e signo na arte.

\section{Da intuição à Representação sensível}

Os conceitos de intuição sensível e representação sensível são analisados por Hegel na seção “Psicologia”, da Enciclopédia das ciências filosóficas, a qual trata especificamente das faculdades ou do modo em geral das atividades do espírito: a intuição, a representação, o pensamento, o desejo, etc. (Hegel, 1995, p. 210). A distinção entre o símbolo e o signo aparece em uma subseção, ligada à faculdade da representação, a qual enfatiza o movimento de externalização dos conteúdos interiormente determinados pelo espírito. Embora essa análise de Hegel se trate de uma descrição longa e complexa, o nosso foco é unicamente o de explicitar o modo segundo o qual tanto a forma da intuição quanto a forma da representação se determinam em relação aos seus dois lados fundamentais, o interno e o externo. A partir disso, caberá igualmente explicar a diferença entre o símbolo e o signo a fim de enfatizar a função que cada um deles desempenha no interior do âmbito artístico.

A intuição sensível se refere a um determinado nível do conhecimento em que a inteligência experimenta a si mesma por meio da simples relação imediata consigo e com o objeto de sua experimentação. Neste estágio do saber, a subjetividade ainda não é refletida a ponto de poder reconhecer-se a si a partir de si mesma e, por isso, ela precisa ainda relacionar-se de modo imediato com a objetividade. Vale lembrar, porém que esta relação de identificação imediata da inteligência com o seu objeto, a qual se articula inicialmente por meio da diferenciação e cisão entre o eu e a coisa exterior, já é uma determinação da racionalidade, a qual já se encontra "penetrada pela certeza do espírito" (idem, p. 224). A inteligência, nesse caso, é apenas uma parte, o lado interior do espírito, que ainda necessita experimentar-se no seu oposto, a exterioridade. Desse modo, a intuição sensível é marcada por três níveis de experimentação da inteligência racional (o espírito) em relação ao seu objeto. Hegel nomeia esses três níveis, respectivamente, de o "grau da sensação", o “grau da atenção" e o "grau da exteriorização".

A primeira forma de experimentação da inteligência em relação ao seu objeto (o qual podemos igualmente nomear de "material” ou de "conteúdo") é a da sensação. A sensação (ou sentimento) é uma “impressão determinada", uma imagem abstrata 
que a inteligência produz em torno do seu objeto. Essa impressão, porém, é ainda uma "determinação simples" (idem., p. 225) da inteligência, pois a forma [Form] do sentimento possui em si o caráter da unilateralidade e da particularidade como a sua marca fundamental. Por causa deste caráter unilateral e abstrato da forma do sentimento, os conteúdos os quais a inteligência imprime para si são igualmente marcados pela ausência de clareza, pois ainda não foram fixados enquanto conteúdos discerníveis. Este nível de inteligibilidade sentimental ainda se refere a um grau rudimentar de desenvolvimento da subjetividade, pois ele aponta para um tipo de representação abstrata, na qual os conteúdos do espírito ainda permanecem em unidade indiferenciada. Este nível de inteligência espiritual ainda não se refere propriamente à intuição sensível, mas é uma aspiração a ela. Pois o sentimento, enquanto material intuído e fixado, ainda é um conteúdo exclusivo da interioridade, ele ainda é uma representação abstrata, unilateral. Nesse nível, igualmente, o subjetivo e o objetivo ainda se unem de modo confuso. 0 que a inteligência toma como conteúdo para si é igualmente confundido com o sentimento que ela possui de si mesma; ela não pode separar por meio da simples imediatidade do sentimento aquilo que se determina como conteúdo em si daquilo que se determina como conteúdo para si. Disso resulta que os conteúdos representados interiormente produzem um tipo de determinação demasiado generalizada e abstrata do espírito; eles são postos na forma do sentimento enquanto unidade não retificada, isto é, não efetivada segundo a racionalidade, "o conceito da coisa" (idem, p. 227) representada na inteligência.

Esse nível inicial da intuição sensível corresponde ao que, no âmbito da arte simbólica, Hegel chamou de "simbolismo inconsciente" e de "simbolismo do sublime". Essas duas fases iniciais de desenvolvimento da arte ainda não se referem propriamente à arte, pelo menos segundo aquilo que é exigido pelo seu conceito. Pois, neste grau de desenvolvimento da inteligência intuitiva, "a exposição sensível não é configurada, formada e inventada a partir do espírito, como exige a arte, mas encontrada e expressa imediatamente na existência exterior como a expressão adequada" (Hegel, 2000, p. 55). Como já foi dito anteriormente, neste nível de intuição ainda não há diferença substantiva entre a alma e o corpo, entre o conceito e a realidade, entre o natural e o humano, tudo o que aparece na exterioridade é determinado como divindade. Por meio do sentimento puro e simples a subjetividade espiritual ainda se encontra numa relação de "unidade imediata com o absoluto", sem nenhuma separação que a diferencie da exterioridade objetiva. Por exemplo, "o sol, os astros, as plantas efetivas e os animais, os homens, o fogo existente, são apreendidos enquanto a forma do absoluto já adequada em sua imediatez" (idem, ibidem).

Hegel considera, igualmente, que esse estado sentimental se refere à primeira forma da "representação poética". Pois, embora "os objetos naturais singulares, assim como os modos singulares de pensar dos homens, os estados, os atos e as 
atividades sejam tomados em sua ausência imediata de significado", ainda assim a forma de apreensão desses objetos prevalece representada como "o uno imediato", isto é, o universal ainda esvaziado de subjetividade (idem, ibidem). Trata-se fundamentalmente de uma representação poética originária ${ }^{11}$ cujo caráter é marcado pelo absoluto, porém, o absoluto representado, particularizado e expressado de modo simbólico e abstrato na alma. A mitologia é o melhor exemplo deste modo de representação poética.

A segunda e a terceira forma de experimentação da inteligência em relação ao seu conteúdo são "a atenção" e "a exteriorização-de-si da inteligência”. A atenção é definida como a etapa da "transformação do objeto sentido em um objeto presente fora de nós” (Hegel, 1995, p. 230). Essa transformação ocorre graças à projeção e à determinação pela inteligência do "sentimento como algo essente" (idem, ibidem), isto é, como algo outro, um estranho, que se difere essencialmente dela própria. Tratase fundamentalmente da projeção do objeto sentido na forma espaço-temporal da exterioridade. $O$ sentimento agora se supera de sua condição espiritual-abstrata e se eleva a sua condição espiritual-concreta na medida em que se transforma em objeto sensível, objetivamente fixado. Entretanto, neste exteriorizar-se-a-si-mesma como aparência objetal, a inteligência projeta na forma e no espaço da exterioridade todo o conteúdo que, em última instância, a determina como inteligência racional, como subjetividade espiritual. Isso quer dizer, ao mesmo tempo, que a inteligência não possui em si mesma outro conteúdo espiritual senão o próprio conteúdo da intuição (idem, ibidem). A exteriorização-de-si da inteligência se refere, neste caso, à fixação de conteúdos racionais, espirituais na forma espaço-temporal da exterioridade, que é a própria intuição objetivamente determinada. Vale lembrar que, para Hegel, a dimensão espaço-temporal da intuição não é uma propriedade reduzida apenas à subjetividade, mas se refere igualmente ao âmbito espaço-temporal dos objetos exteriormente determinados. Portanto, a intuição sensível se determina como unidade imediata marcada por dois momentos: "o momento de ser interiorizada [erinnert] em si mesma neste material essente de modo exterior; e o momento de ser, em sua interiorização-em-si-mesma, imersa no ser-fora de si” (idem, ibidem).

Todavia, se o fundamento do movimento de exteriorização de si da inteligência se deve tanto ao fato de ela não possuir em si mesma outras formas mais elevadas de determinação dos conteúdos espirituais, quanto ao fato de seus conteúdos não serem outros senão aqueles materiais do sentimento, logo, aquilo que a determina como espírito absoluto, como inteligência racional, só pode ser encontrado de modo completo na objetividade. É essa objetividade substancial que encontramos, por exemplo, na

11 Hegel distingue dois níveis da representação poética: o primeiro ele nomeia de "a representação poética originária", o qual está ligado ao "ideal simbólico", e o segundo nível, da "representação poética que se constitui a partir da prosa", que está ligado ao ideal romântico da arte. Sobre os desdobramentos dessa distinção, conferir Hegel, 2004, pp. 50-55. 
forma de arte clássica. Segundo a compreensão de Hegel, o antropomorfismo do deus grego é a mais bela e concreta expressão imediato-sensível da unidade entre o subjetivo e o objetivo. Nesse registro, o interior possui imediatamente a forma da exterioridade enquanto idêntica a si mesmo (Hegel, 2000, p. 157). A subjetividade, aqui representada [Darstellung] por meio da corporeidade da estátua do deus-homem, se desprende de sua condição de ser simples "subjetividade comparativa invisível" (idem, p. 161) e alcança para si a dignidade de ser a interioridade que se relaciona consigo mesma objetivamente. Nesse sentido, toda a determinação mais concreta e efetiva do espírito passa fundamentalmente para o lado da exterioridade sensível algo que, em última instância, condiciona a subjetividade à plena imediatidade sensível.

Todavia, a subjetividade espiritual é marcada por um segundo momento neste movimento de determinação de si mesma, no qual ela está posicionada para além dessa sua determinação intuitivo-sensível. Trate-se precisamente do momento da representação [Vorstellung] sensível. A representação sensível pode ser denominada igualmente de "intuição rememorada" (Hegel, 1995, p. 234), ela é "o meio termo entre $o$ achar-se-determinado imediato da inteligência e a inteligência em sua liberdade, o pensar" (idem, ibidem). De acordo com Hegel, o movimento aqui é o da interiorização dos conteúdos antes representados [Darstellung] e intuídos exteriormente. Vale lembrar que a representação sensível desse momento não deve ser confundida com aquela "representação abstrata", pautada exclusivamente no sentimento puro. Aqui, ao contrário, os conteúdos da representação sensível são resultados da objetividade substancial, isto é, já são conteúdos concretos intuídos pela dimensão espaço-temporal subjetiva e objetiva. Nesse registro, "o espírito põe a intuição como a sua, a penetra, e dela faz algo interior, nela se interioriza, tornase nela presente a si mesmo, e, portanto, livre" (idem, ibidem). Nesse sentido, a inteligência se emancipa da sua dependência da exterioridade, transformando o conteúdo absoluto em uma propriedade exclusivamente sua.

A representação sensível se constitui a partir de três níveis distintos: a rememoração, a imaginação e a memória. A rememoração é o estágio em que a intuição é elevada ao âmbito da representação interior. Trata-se da elevação do objeto intuído em sua singularidade à dignidade da particularidade representacional a qual, por sua vez, já é mediada pelo universal, o espírito. Nesse estágio, a representação se mantém no campo da intuição, pois o seu conteúdo é a imagem (idem, p. 238). Assim, a recordação se define como imagem interiorizada, formulada segundo os moldes da representação. Aqui há uma duplicação da imagem: ela se apresenta tanto como propriedade do eu, quanto ainda persiste como algo fora do eu, no exterior. Isto é, para que a imagem interior esteja vigente ela necessita, entretanto, de uma outra imagem exterior que seja para ela um ponto de referência. Nessa direção, a imaginação é o próximo estágio, o qual consiste em livrar a representação 
da necessidade desse ponto de fixação exterior.

A imaginação é definida por Hegel como a instância que universaliza a recordação, que a atualiza no plano universal das "associações livres" (idem, p. 240), as quais independem da imagem exterior para se fazerem presentes, já que se tratam de movimentos de "subsunção das representações singulares" (idem, ibidem). Dito de outro modo, o trabalho da imaginação consiste em transformar a imagem singular em ideia concreta. Mas é preciso observar, ao mesmo tempo, que essa elevação da imagem à dignidade de representações universais produz um efeito de condensação e síntese, cujo ponto de partida se dá no ser-aí da imagem intuída, e não no ser-aí da própria imaginação. Ou seja, nesse estágio, a imaginação ainda não está separada totalmente da intuição, o que corresponde afirmar que a imaginação ainda é dependente da imagem sensível, ainda que ela seja capaz de, no interior de suas associações, elaborar outros conteúdos para além desse referente sensível. Esse referente, por sua vez, nada mais é senão um símbolo; o signo, ao contrário, é o ser-aí sensível que estabelece a separação completa entre a imaginação e a intuição.

Aqui nos deparamos com a introdução da noção de fantasia, a qual se determina inicialmente como o nível mais abstrato da imaginação, cujo caráter simbólico é índice de um certo afastamento da imagem sensível, mas ainda um afastamento que deixa inscrito na imaginação uma marca da imagem sensível. Hegel considera, nesse sentido, dois níveis distintos de determinação da fantasia, o primeiro, por assim dizer mais abstrato, e o segundo nível mais concreto. Trata-se precisamente da distinção entre "fantasia simbolizante e fantasia significante" (Hegel, 1995, p. 241). O lado exterior desta distinção dos níveis da fantasia incide, ao mesmo tempo, na diferenciação da função desempenhada pela imagem-símbolo e pela imagemsígnica, ou, simplesmente, pelo símbolo e pelo signo (idem, ibidem).

\section{Da imagem-símbolo à imagem-sígnica}

Segundo Hegel, a fantasia simbolizante é a versão inicial da “imaginação produtora”, a qual "constitui o princípio formal da arte” (idem, p. 244). Como já foi dito, a fantasia simbolizante é um tipo de imaginação ainda condicionada à função intuitivo-sensível da imagem, pois “ela não escolhe para expressão de suas representações universais nenhum outro material sensível a não ser aquele cuja significação autônoma corresponde ao conteúdo universal a ser figurado em imagens" (idem, p. 241). Assim, a imagem exterior é idêntica ao significado interior, o universal está em unidade diferençável com o singular. Por exemplo, na imagem do leão já está contido de modo imediato a ideia da força, assim como na imagem da cruz cristã já está determinada a ideia do Deus. Entretanto, o simbólico não se define apenas por meio dessa identificação, mas igualmente pelo grau de contingência envolvida na ideia que ele veicula; a figura do leão, assim como a imagem da cruz, se referem 
a outras infinitas significações, por exemplo, a coragem, a altivez, o sofrimento, a dor e etc.

Ao contrário da fantasia simbolizante, a fantasia significante configura um nível superior da imaginação produtora, no qual a cisão entre a imagem sensível e a representação interior do seu significado ocorre de modo completo. Nesse grau de inteligibilidade, a imaginação não está mais condicionada à função significante da imagem sensível, o que corresponde dizer, ao mesmo tempo, que a função intuitivosensível da imagem perde a sua razão de ser e adquire, nessa perda, uma nova função: a da abstração. A fantasia significante ao instaurar-se para si um âmbito pleno de conteúdo e significado (o âmbito da representação interior), ela acaba, ao mesmo tempo, modificando a função concreta da imagem exterior, a qual, por sua vez, passa a estar à serviço exclusivo da fantasia. Se no nível da fantasia simbolizante a imagem sensível cumpre a tarefa de organizar os conteúdos difusos no âmbito da intuição sensível, no nível da fantasia significante, ao contrário, a imagem sensível cumpre a função de separar de si a sua dimensão sensível do seu significado autêntico. A exemplo disso, "um emblema nacional ou uma bandeira ou uma pedra tumular significam uma coisa totalmente diversa do que imediatamente indicam" (idem, p. 246). Nesse sentido, nos lembra Hegel, a imagem-sígnica "é uma imagem que recebeu em si mesma, como alma, uma representação autônoma: sua significação" (idem, p. 248).

Nessa modificação estrutural do conceito de imagem podemos observar, ainda, uma modificação significativa do caráter de arbitrariedade que incide tanto no nível da fantasia simbolizante quanto no nível da fantasia significante. Isto é, enquanto no grau da fantasia simbolizante a dimensão que se mantém contingente e arbitrária é a dimensão do significado e do conteúdo espiritual, no nível da fantasia significante, ao contrário, o que permanece arbitrário é a própria dimensão sensível da imagem, já que o significado dela mesma se estabelece como uma propriedade exclusiva da representação interior ou, se preferirmos, da fantasia. Nesse sentido, a imagemsígnica é uma espécie de "ser-posto pela inteligência" (idem, ibidem), um produto objetivo cujo conteúdo de verdade, porém, está estruturado de modo concreto e exclusivo no interior da subjetividade. Nas palavras de Hegel, a imagem-sígnica cumpre a função de fornecer "às sensações, intuições, representações uma segunda existência, superior à sua existência imediata; e uma existência que vigora no reino da representação" (idem, ibidem).

Nesta distinção entre os níveis da fantasia (e a influência destes graus de inteligibilidade na função da imagem-símbolo e na função da imagem-sígnica) encontramos a justificação completa para entender a beleza romântica-moderna como predominantemente sígnica. Pois, no âmbito da estética de Hegel esses níveis de inteligibilidade correspondem ao desenvolvimento da subjetividade espiritual por intermédio do caráter sensível-imediato da arte. Como já foi dito anteriormente, 
o grau mais elevado deste desenvolvimento ocorre no âmbito da arte romântica, quando a subjetividade se torna significativa por si mesma e se explica a si mesma (Hegel, 2000, p. 35). Nesse registro, o espírito já se livrou da dependência do material exterior, já que a fantasia constitui para si o próprio conteúdo ou material de suas representações mais elevadas (Hegel, 2004, p. 19). O impasse implicado nessa interiorização, porém, é o da condução desses conteúdos universais até a expressão singular das obras de arte.

Nesse sentido, a singularidade artística é desafiada a cumprir duas tarefas essenciais no que tange à determinação autêntica do conceito de arte moderna. De um lado, ela precisa ser a expressão objetiva dos conteúdos mais elevados do espírito. Entretanto, de outro lado, ela deve apresentar esses conteúdos como recriação subjetiva da exterioridade, já que a fantasia, a imaginação produtora, é a reorganização e a recriação dos conteúdos objetivamente intuídos, no âmbito das representações interiores. É por meio da função da imagem-sígnica que a arte romântica-moderna se determina tanto como "aparência sensível da ideia" ou "signo da ideia", quanto como "recriação subjetiva da exterioridade no elemento sensível das cores e da luz" (Hegel, 2000, p. 335), igualmente, no elemento do som, da palavra e seu sistema, a linguagem (Hegel, 1995, p. 248). Pois, enquanto imagem representacional, a imagem-sígnica é, ao mesmo tempo, concreta porque expressa um significado espiritual concreto (subjetivo), e objetivamente abstrata em si mesma, porque se refere a algo outro. Essa ausência de concretude objetiva da imagem-sígnica é tanto índice do caráter contingente da realidade objetiva, quanto é exatamente aquilo que concede à arte o "poder de criar uma objetividade" (Hegel, 2000 , p. 335). Em suma, enquanto imagem-sígnica, o belo artístico românticomoderno se define como produto da expressão e, simultaneamente, da recriação subjetiva e objetiva do espírito.

De acordo com Hegel, esse poder de recriação subjetiva e objetiva da realidade se encontra, antes de tudo, nas mãos do artista moderno: "toda forma [Form] assim como toda matéria estão agora a serviço e à oferta dele, cujo talento e gênio estão libertados para si mesmos da limitação anterior a uma forma [Form] de arte determinada.” (idem, p. 341). Essa liberdade plena de criação, entretanto, não deve se furtar à exigência de que o "conteúdo constitua para o artista o substancial, a verdade mais interior de sua consciência” (idem, p. 339), já que “o conteúdo [Gehalt], como toda obra humana, também na arte é o que decide" (idem, p. 346). Frente a essa exigência, a imagem-sígnica, enquanto este "objeto novo, belo, em si mesmo pleno de valor" (idem, ibidem), funciona igualmente como uma espécie de termômetro que mede a capacidade do artista em trazer à exterioridade um conteúdo substancial, que apareça tanto como expressão quanto como recriação do espírito. 


\section{Referências}

De Man, P. (1982). Sign and Symbol in Hegel's Aesthetics. Critical Inquiry, 8(4), 761 775.

Farina, M. (2015). Crítica, simbolo e storia: la determinazione hegeliana dell'estetica. Piza: Edizioni ETS.

Hegel, G. W. F. (1976). Jenaer Systementwürfe III. In: Gesammelte Werke, Band 8. Herausgegeben von Horstmann, Rolf-Peter und Trede, Johann Heinrich. Düsseldorf: Felix Meiner.

Hegel, G. W. F. (1989). Enzyklopädie der philosophischen Wissenschaften im Grundrisse (1827). In: Gesammelte Werke, Band 19. Herausgegeben von Wolfgang Bonsiepen und Hans Christian Lucas. Düsseldorf: Felix Meiner.

Hegel, G. W. F. (1995a). Vorlesungsmanuskripte II (1816-1831). In: Gesammelte Werke, Band 18. Heausgegeben von Walter Jaeschke. Düsseldorf: Felix Meiner.

Hegel, G. W. F. (1995b). Enciclopédia das ciências filosóficas (1830). Vol. 1 e 3. (A Filosofia do Espírito) Trad. de Paulo Meneses e Pe. José Machado. São Paulo: Loyola.

Hegel, G. W. F. (1999; 2000; 2004). Cursos de estética (Vol. 1, 2 e 4). Trad. De Marco Aurélio Werle e Oliver Tolle. São Paulo: EDUSP.

Hegel, G. W. F. (2001). Enzyklopädie der Philosophischen Wissenschaften im Grundrisse (1817). In: Gesammelte Werke, Band 13. Herausgegeben von Wolfgang Bonsiepen und Klaus Grotsch. Hamburg: Felix Meiner.

Jaeschke, W. (2020). Hegels Philosophie. Hamburg: Felix Meiner.

Lauener, H. (2004). A linguagem na filosofia de Hegel. Trad. de Paulo Rudi Schneider. Ijuí: Unijuí.

Schlegel, F. (2016). Conversa sobre a poesia e outros fragmentos. Trad. e notas de Constantino Luz de Medeiros e Marcio Suzuki. São Paulo: Unesp.

Szondi, P. (1974). Poetik und Geschichtsphilosophie I. Studienausgabe der Vorlesungen, Band 2. Frankfurt: Suhrkamp Verlag.

Werle, M. A. (2005). A poesia na estética de Hegel. São Paulo: Humanitas/FAPESP. 